\title{
Occupational factors in hypertension in the Nigerian African
}

V. O. OVIASU

From the Department of Medicine, University of Benin, Benin City, Nigeria

F. E. OKUPA

From the Department of Medicine, University of Benin Teaching Hospital, Benin City, Nigeria

SUMMARY In cross-sectional surveys of arterial blood pressure carried out in rural and urban communities in the Bendel State of Nigeria, mean systolic and diastolic pressure was generally higher in urban than in rural subjects but the differences in particular age groups were statistically significant only in some of them. Two sample Student's $t$ tests were carried out to compare the blood pressure of rural labourers, rural clerks, and urban clerks. It is not clear from our findings whether the differences in any particular age group between rural labourers and urban clerks should be attributed to occupation or to area of residence. However, the consistently intermediate values for rural clerks over the different age groups provide strong indirect evidence that both these factors are relevant.

Many reports have shown that the arterial blood pressure of the urban African is generally higher than that of his rural counterpart (Scotch, 1960; Scotch et al., 1961; Akinkugbe and Ojo, 1969; Pobee et al., 1977). Although many factors are known that could modify blood pressure, no reasons based on comparative studies have been produced to explain the difference in pressure between the urban and rural African. The possible influence of occupations with different degrees of physical activities has not been examined. With this omission in mind, an attempt has been made to measure the blood pressure of a group of African field labourers and office clerks, in the hope that differences in occupation might explain in part the differences in blood pressure.

\section{Methods}

Two populations in the Bendel State of Nigeria were defined-one rural, the other urban-and the study was carried out in two stages.

\section{SUBJECTS}

Rural Study

Isiuwa village, a conglomeration of what were originally three smaller villages, is situated $36 \mathrm{~km}$ north-west of Benin City.
The village occupies 1735 hectares of rolling countryside in the equatorial forest zone of Bendel State. The residential village is spread overo 122 hectares of land and the remaining land is devoted to the growing of oil palm, coconut, and raphia palms. The population of Isiuwa village is about 5000 (private census, 1976). The head of every household is employed at the Nigerian Institute for Oil Palm Research (NIFOR). NIFOR has overall responsibility for the administration and welfare of Isiuwa village. NIFOR is also responsible for the cultivation of oil palms and the production of oil from the extensive palm plantation at the village.

Of the total of 1500 male adults aged 15 to 60 resident in the village, 400 men work in the offices of NIFOR and 1100 men work as field labourers. Of the field labourers, 330 men (30\%) were literate, judged by ability to read and write. Most of the 750 adult women who were in Isiuwa village at the time of the survey were engaged in subsistence farming and 'petty trading'.

During the months of June and July 1976, 1482 men and 600 women were examined.

\section{Urban Study}

Benin City with a population of about 200000 (government census, 1963) is the capital city of Bendel State of Nigeria. The study was concerned 
with the clerical workforce of the state capital's secretariat. The secretariat is situated in the centre of the city and houses 12 government Ministries (departments). At the time of the survey 970 males and 360 females aged between 15 and 60 were employed in the secretariat; 179 males $(18.5 \%)$ and 34 females $(9 \cdot 4 \%)$ work as senior administrative staff by being at the head of the various subunits staffed by junior clerical workers. During the months of September, October, and November, 1977, 916 males and 347 females were examined.

In both the rural and the urban surveys blood pressure readings were taken using a standard mercury sphygmomanometer with a cuff size of $12 \times 22 \mathrm{~cm}$. All measurements were taken in the left arm between 09.00 and 13.00 hours, after the subjects had been seated for five minutes. The systolic blood pressure (SBP) was taken at the first appearance of sound. The diastolic blood pressure (DBP) was taken at the point when there was an abrupt muffling of sound (phase 4).

Using a standard questionnaire, information was obtained from the respondents about name, address, age, sex, occupation, marital and educational status, and position held at work. To confirm the accuracy of statements about age, especially in doubtful cases, the respondents were encouraged to relate their age to local historical records, such as dates of traditional festivities, missionary activities, national events, and the coronation of local kings. The general appearance of the subjects was sometimes relied on; and in the case of illiterate women, the years of marriage, the ages of their firstborn, and the onset of menopause helped to verify age. It was considered futile to attempt to estimate age more accurately than by five-year groups. The height and weight of all respondents was measured without shoes and with light clothing. Quetelet's index of body mass was calculated for each subject as weight $(\mathrm{kg}) / \mathrm{height}^{2}(\mathrm{~cm}) \times 100$ (Khosla and Lowe, 1967). All respondents were asked about their smoking habits.

Urine samples from all the respondents were examined for protein and sugar using uristix strips (Ames).

For this study hypertension was defined as SBP of $160 \mathrm{~mm} \mathrm{Hg}$ and above, or DBP of $100 \mathrm{~mm} \mathrm{Hg}$ and above, or a combination of both. Subjects with blood pressure below these given levels were considered normotensive.

\section{Results}

\section{Response rates}

In the rural survey 387 male office clerks and 1095 male field labourers were examined, giving response rates of $96.8 \%$ and $99.5 \%$ respectively. The number of women examined in the rural survey was 600 , giving a response rate of $80 \%$.

In the urban survey 916 males and 347 females were examined, giving response rates of $94.4 \%$ and $96 \cdot 4 \%$ respectively.

\section{Mean arterial pressures}

Mean SBP and DBP for the entire rural and urban populations is expressed graphically in Fig. 1 (rural and urban males) and Fig. 2 (rural and urban females). It can be seen that, for both males and females, mean arterial blood pressure for the urban populations was generally higher than for the rural populations.

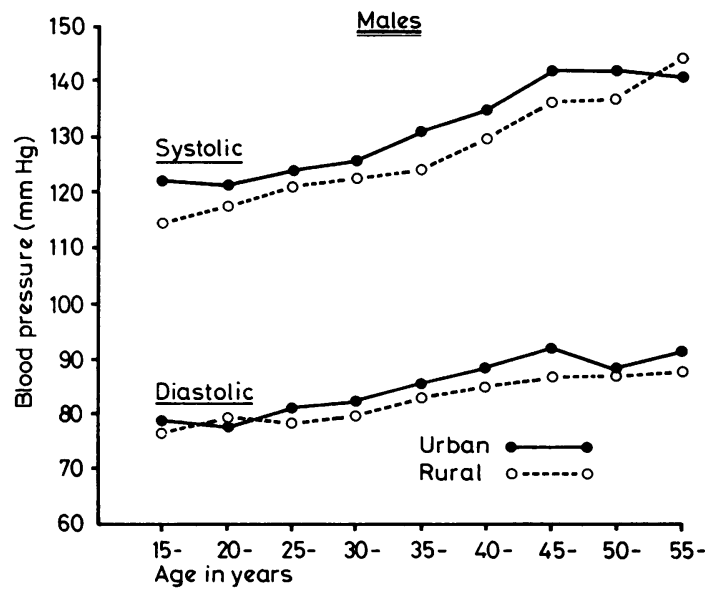

Fig. 1 Mean systolic and diastolic blood pressure of urban and rural males.

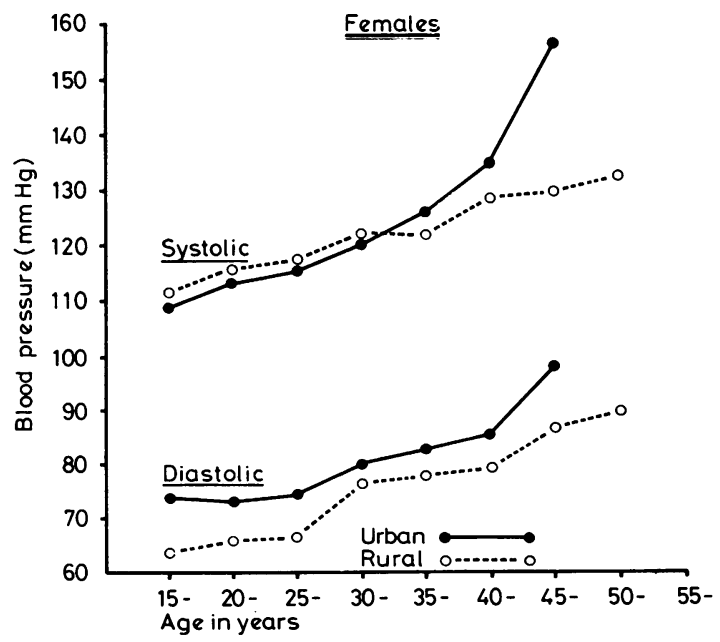

Fig. 2 Mean systolic and diastolic blood pressure of urban and rural females. 
The statistical significance of the differences in mean blood pressure between the rural and urban populations is expressed in Table 1.

Table 2 shows the mean SBP and DBP with their standard deviations (SD) of rural clerks and rural labourers and Fig. 3 shows the mean values of the SBP and DBP of rural clerks, rural labourers, and urban clerks. It can be seen that rural clerks had higher SBP and DBP than rural labourers, and that urban clerks had higher SBP and DBP than rural clerks.

Two sample Student's $t$ tests were carried out to compare the mean blood pressure of rural clerks with that of rural labourers and also the mean blood pressure of rural clerks with that of urban clerks. None of the comparisons was significant.

\section{Quetelet's index and blood pressure}

Fig. 4 shows that as SBP increased with age the Quetelet indices also increased with age in rural clerks and only slightly in rural labourers. However, the differences in the Quetelet indices in each particular age group were not statistically significant.

Table 1 Two sample Student's t test statistics for comparing mean blood pressure in different samples

\begin{tabular}{|c|c|c|c|c|}
\hline \multirow{3}{*}{$\begin{array}{l}\text { Age group } \\
\text { (years) }\end{array}$} & \multirow{2}{*}{\multicolumn{2}{|c|}{$\frac{\text { MALES }}{\text { Rural v Urban }}$}} & \multirow{2}{*}{\multicolumn{2}{|c|}{$\frac{F E M A L E S}{\text { Rural v Urban }}$}} \\
\hline & & & & \\
\hline & Systolic & Diastolic & Systolic & Diastolic \\
\hline $\begin{array}{l}15-19 \\
20-24 \\
25-29 \\
30-34 \\
35-39 \\
40-44 \\
45-49 \\
50-54 \\
55-59\end{array}$ & $\begin{array}{l}-1.73 \\
-2.34^{*} \\
-2.00^{*} \\
-1.60 \\
-3.36^{* * *} \\
-2.19 \\
-1.37 \\
-1.05 \\
0.09\end{array}$ & $\begin{array}{l}-0.50 \\
-0.45 \\
-1.82 \\
-1.38 \\
-1.55 \\
-2.58 * * \\
-3.18^{* *} \\
-0.77 \\
-0.83\end{array}$ & $\begin{array}{r}1.00 \\
1.63 \\
1.01 \\
0.70 \\
-0.69 \\
-0.77 \\
-2.36^{\circ} \\
- \\
-\end{array}$ & $\begin{array}{l}-4 \cdot 69^{* * *} \\
-4 \cdot 56^{* * *} \\
-5 \cdot 20^{* * *} \\
-1 \cdot 88 \\
-1 \cdot 22 \\
-1 \cdot 12 \\
-1 \cdot 83 \\
- \\
-\end{array}$ \\
\hline
\end{tabular}

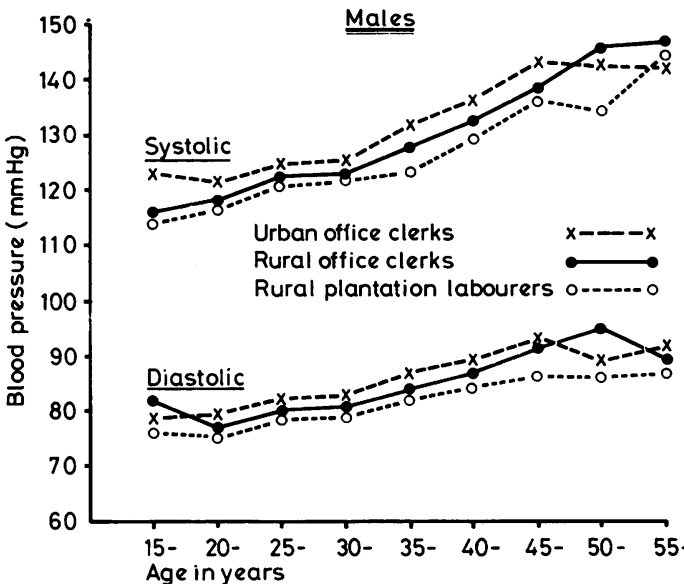

Fig. 3 Mean systolic and diastolic blood pressure of rural clerks, rural labourers, and urban clerks.

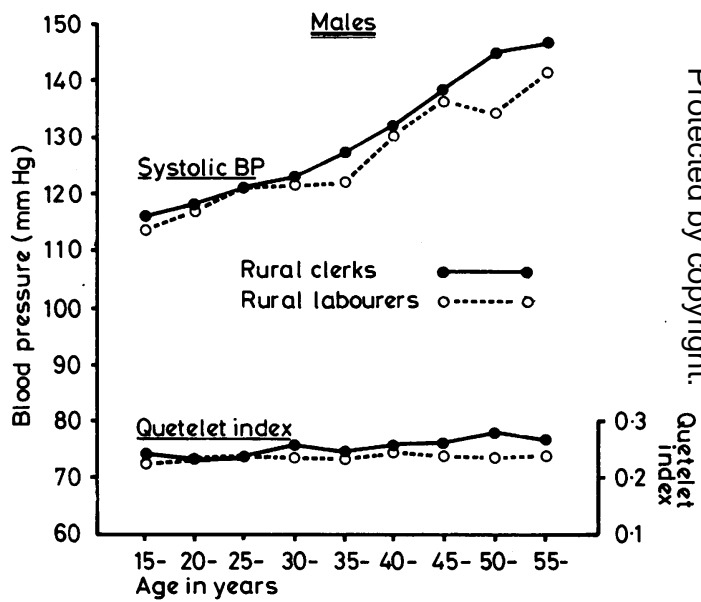

Fig. 4 Relationships between blood pressure and Quetelet indices (rural males).

Table 2 Mean systolic and diastolic blood pressure, rural males

\begin{tabular}{|c|c|c|c|c|c|c|c|c|c|c|}
\hline \multirow{3}{*}{$\begin{array}{l}\text { Age group } \\
\text { (years) }\end{array}$} & \multicolumn{5}{|c|}{ RURAL CLERKS } & \multicolumn{5}{|c|}{ RURAL LABOURERS } \\
\hline & \multirow[b]{2}{*}{ No. } & \multicolumn{2}{|c|}{ Systolic } & \multicolumn{2}{|c|}{ Diastolic } & \multirow[b]{2}{*}{ No. } & \multicolumn{2}{|c|}{ Systolic } & \multicolumn{2}{|c|}{ Diastolic } \\
\hline & & Mean & $S D$ & Mean & $S D$ & & Mean & $S D$ & Mean & $S D$ \\
\hline $\begin{array}{l}15-19 \\
20-24 \\
25-29 \\
30-34 \\
35-39 \\
40-44 \\
45-49 \\
50-54 \\
55-59\end{array}$ & $\begin{array}{r}10 \\
87 \\
115 \\
59 \\
44 \\
40 \\
20 \\
7 \\
5\end{array}$ & $\begin{array}{l}114.0 \\
116.8 \\
119.5 \\
121.0 \\
125.5 \\
129.8 \\
135.5 \\
142.9 \\
144.0\end{array}$ & $\begin{array}{r}8.0 \\
9.4 \\
15.7 \\
19.5 \\
18.6 \\
17.7 \\
22.7 \\
21.9 \\
20.6\end{array}$ & $\begin{array}{l}80.0 \\
75.9 \\
77.9 \\
79.5 \\
82.3 \\
85.0 \\
89.5 \\
92.9 \\
88.0\end{array}$ & $\begin{array}{r}7.4 \\
9.6 \\
10.3 \\
15.6 \\
11.4 \\
11.4 \\
12.4 \\
13.9 \\
13.1\end{array}$ & $\begin{array}{r}12 \\
87 \\
221 \\
227 \\
191 \\
157 \\
116 \\
59 \\
25\end{array}$ & $\begin{array}{l}112.5 \\
115.5 \\
119.5 \\
120.5 \\
121.1 \\
128.2 \\
135.0 \\
132.0 \\
140.8\end{array}$ & $\begin{array}{l}15 \cdot 3 \\
14 \cdot 6 \\
17.6 \\
18 \cdot 4 \\
18.6 \\
20 \cdot 6 \\
28.1 \\
26.9 \\
32.6\end{array}$ & $\begin{array}{l}75.8 \\
76.1 \\
77.7 \\
78.2 \\
80 \cdot 3 \\
82.6 \\
84.0 \\
83.9 \\
84.6\end{array}$ & $\begin{array}{r}11.1 \\
7.9 \\
11.1 \\
11.0 \\
13.9 \\
12.1 \\
12.7 \\
13.9 \\
11.2\end{array}$ \\
\hline Total & 387 & 127.7 & $17 \cdot 1$ & 83.4 & $11 \cdot 6$ & 1095 & $124 \cdot 9$ & $21 \cdot 4$ & 80.3 & 11.6 \\
\hline
\end{tabular}


A rise in blood pressure and in the Quetelet indices with age was also found in both male and female urban subjects.

\section{Blood pressure of literate and illiterate labourers}

Mean SBP and DBP were calculated for 30 literate labourers sampled from each of the age groups 35-39 and $40-44$ and compared with a similar number of illiterate labourers from the same age groups. No significant differences in mean pressure were found.

\section{Urinalysis}

Among the rural subjects, 79 males (5.3\%) and 36 females $(6.0 \%)$ had proteinuria. Among the urban subjects, 98 males $(10 \cdot 7 \%)$ and 28 females $(8 \cdot 1 \%)$ had proteinuria. Among the subjects with proteinuria, the finding of pus cells and/or hyaline casts on microscopic examination of their urine suggested renal disease related to high blood pressure in only one male in the rural community and three subjects (two males and one female) in the urban community.

\section{Smoking and blood pressure}

Eight males (2\%) among the rural clerks and 12 males $(1 \cdot 1 \%)$ among the rural labourers smoked between five and 10 cigarettes daily. In the urban survey 27 males $(2 \cdot 5 \%)$ smoked between five and 10 cigarettes daily. The habit of smoking was not encountered in any of the rural and urban females.

The small number of smokers encountered in this study were all normotensive.

\section{Discussion}

High blood pressure is considered to be the result of environmental influences acting over time on the genetically predisposed individual (Pickering, 1967). The rural and urban communities studied here provided an ideal location for studying occupational factors because hypertension is very prevalent in the Nigerian African.

In this study our findings confirmed that the mean SBP and DBP of urban subjects was generally higher than that of rural subjects in comparable age groups but the differences were only statistically significant in the age groups $35-49$ in males. For females the differences in DBP were statistically significant in the age groups 13-29. Previous reports (Scotch, 1960; Scotch et al., 1961; Akinkugbe and Ojo, 1969; and Pobee et al., 1977) have been silent on the issue of statistical significance of the differences in the mean arterial pressure found between rural and urban subjects. It is, however, not known whether the difference is due to occupation or to environment.
This study has clearly shown the consistently higher mean arterial pressure of one occupational group over the other, even where both occupational groups share a common environment. Rural office clerks had higher mean arterial pressure than rural field labourers and urban office clerks had higher mean arterial pressure than rural clerks (Fig. 3).

Our findings of higher blood pressure in rural male clerks than in rural male labourers bear apparent similarities to those of Miall (1959) who found that arterial pressure was significantly higher in men previously employed mainly in light occupations than in those in heavy occupations. Miall claimed support for his findings from the occupational mortality supplement of the Registrar General (1958) where it was reported that standardised mortality ratios for hypertension, vascular lesions of the central nervous system, and coronary disease were greatly increased in the light occupation groups.

Morris and Crawford (1958) have suggested a relationship between physical activity, hypertension, and ischaemic heart disease. In their analysis of a national necropsy survey they found that hypertension, based on clinical and pathological findings, was less common and occurred 10 to 15 years later in men previously employed in heavy occupations than in others.

Quetelet's index was chosen as an index of body mass based on a review of population weight for height because it was considered as the least correlated with height and the most correlated with independent measurements of obesity (Khosla and Lowe, 1967). Our findings showed that subjects with higher blood pressure also had higher Quetelet indices. However, the differences in the Quetelet indices between the rural clerks and labourers were not statistically significant. Although the association of weight with blood pressure has been well documented (Kannel et al., 1967; Miall et al., 1968; Ashley and Kannel, 1974) we are unable to show from our findings that the differences in arterial pressure between rural and urban subjects are due to weight.

The number of subjects in our study who smoked cigarettes was small and the number they smoked (five-10 cigarettes daily) is also small compared with those studied in the reports of Stamler et al., (1975). We do not consider that smoking had any influence on our findings. Stamler $e t$ al., in a report based on cross-sectional and prospective epidemiological studies in Chicago, found no positive relationship between cigarette smoking and blood pressure.

The rural clerks and rural labourers studied both share a common environment, drink water from the same stream, and eat predominantly high carbohydrate diets with vegetable oil, some meat, 
and fish. No attempt was made to estimate the salt intake of the subjects studied. Dahl and Love (1954; 1957) presented evidence that those who take additional salt with their food at table have higher blood pressure than those who do not.

The occupations of our subjects, however, differ in degrees of physical activities. The clerks are in sedentary occupations while the labourers are physically active clearing, planting, and harvesting palm nuts. The subjects also differ in literacy. All the clerks are literate, but only $30 \%$ of the field labourers. Important differences in mean blood pressure might arise when comparing two groups, one literate and one illiterate. Distribution of blood pressure is also known to be influenced by socioeconomic, cultural, and educational factors. However, in this study important differences in mean pressure have not been found between the literate and illiterate labourers sampled from the age groups 35-39 and 40-44 where the numbers of subjects allowed for such comparison. We do not think, therefore, that educational factors could account for the differences in mean pressure between the field labourers and the office clerks.

In conclusion, it is not clear from our findings whether the differences in any particular age groups between rural labourers and urban clerks should be attributed to occupation, or to area of residence. However, the consistently intermediate values for rural clerks over the different age groups provide strong indirect evidence that both these factors are relevant.

We thank the Director of NIFOR, Dr. Okaisabor, and the Head of the Civil Service, Mr. J. T. L. Boyo, for permission to examine members of their staff. Dr. Mary Fulton and Dr. Robb Elton of Edinburgh University gave useful advice during the preparation of the manuscript for which we are very grateful. A grant from the Nigerian Medical Research Council made it possible to undertake this project.

Reprints from Dr. V. O. Oviasu, Associate Professor, Department of Medicine, University of Benin, Benin City, Nigeria.

\section{References}

Akinkugbe, O. O., and Ojo, O. A. (1969). Arterial pressures in rural and urban populations in Nigeria. British Medical Journal, 2, 222-224.
Ashley, F. W., and Kannel, W. B. (1974). Relation of weight change to changes in atherogenic traits: The Framingham Study Journal of Chronic Diseases, 27, 103-114.

Dahl, L. K., and Love, R. A. (1954). Evidence of relationship between sodium chloride intake and human essential hypertension. Archives of Internal Medicine, 94, 525-531.

Dahl, L. K., and Love, R. A. (1957). Aetiological role of sodium chloride in essential hypertension in humans. Journal of the American Medical Association, 164, $397-400$.

Government Census (1963). Midwest Statistical Note Book, vol. 2, 1972. Ministry of Economic Development and Reconstruction: Benin City.

Khosla, T., and Lowe, C. R. (1967). Indices of obesity derived from body weight and height. British Journal of Preventive and Social Medicine, 21, 122-128.

Kannel, W. B., Brand, N., Skinner, J. J., Dawber, T. R., and Mc Namara, P.M. (1967). The relation of adiposity to blood pressure and development of hypertension: The Framingham Study. Annals of Internal Medicine, 67, 48-59.

Miall, W. E. (1959). Follow-up study of arterial pressure in the population of a Welsh mining valley. British Medical Journal, 2, 1204-1210.

Miall, W.E., Bell, R. A., and Lovell, H. G. (1968). Relation between change in blood pressure and weight. British Journal of Preventive and Social Medicine, 22, 73.

Morris, J. N., and Crawford, M. D. (1958). Coronary heart disease and physical activity of work; evidence of a national necropsy survey. British Medical Journal, 2,

Pobee, J. O. M., Larbi, E. B., Belcher, D. W., Wurapa, F K., and Dodu, S. A. (1977). Blood pressure distribution in a rural Ghanaian population. Transactions of the Royal Society of Tropical Medicine and Hygiene, 71, 66-72.

Pickering, G. (1967). The inheritance of arterial pressure In The Epidemiology of Hypertension, p. 18. Edited by J. Stamler, R. Stamler, and T. Pullman. Grune and Stratton New York.

Private Census (1976). Conducted by the Department of Community Medicine, University of Benin, Nigeria.

Registrar General (1958). Decennial Supplement, England and Wales, 1951. Occupational Mortality, Part II. HMSO: London.

Scotch, N. A. (1960). A preliminary report on the relation of sociocultural factors to hypertension among the Zulu. Annals of the New York Academy of Sciences, 84, 1000

Scotch, N., Gampel, B., Abramson, J. H., and Slome, C. (1961). Blood pressure measurements of urban Zulu adults. American Heart Journal, 61, 173-177.

Stamler, J., Berkson, D. M., Dyer, A., Lepper, M. H., Lindberg, H. A., Oglesby Paul, Mckean, H., Rhomberg, P., Schoenberger, J. A., Shekelle, R. B., and Stamler, R. (1975). Relationship of multiple variables to blood pressure-findings from four Chicago epidemiological studies. In Epidemiology and Control of Hypertension, pp. 307-351. Edited by Oglesby Paul. Stratton: New York and London. 